\title{
Economic Impact of the Telecommunication Industry on Bangladesh
}

\author{
Zaheed Husein Mohammad Al-Din
}

\begin{abstract}
The revolution of cellular telecommunication in Bangladesh started when the first call was made in 1989. This sector has a massive effect on the economy of the country. The GDP of the country has grown from less than 30 Billion US Dollars to 130 Billion US Dollars during 1989-2015 which is almost 4 times. Before the first mobile operator set foot on Bangladesh, people were heavily dependent on the BTTB Phones which are very popularly known as T\&T Phone Lines. Although Bangladesh has one of the highest call rates in the world, the mobile penetration is at the very high end. The six operators together serve a customer base of 120 million as of December 2014. When one looks at the overall contribution of these operators towards the economy of the country then one would unquestionably be in agreement with the contribution that these companies and their employees have towards the economy.
\end{abstract}

Keywords - telecommunication, mobile phone, employees

\section{Introduction}

It was the year 1989 when the first phone call was made using a mobile connection of an operator in Bangladesh. Since then the revolution has started and it is still ongoingthe revolution of telecommunication sector in Bangladesh. This sector had a significant effect on the economy of the country. However, to what extent did it affect the economy of the 8th most populous country in the world? The GDP of the country has grown from less than 30 Billion US Dollars to 130 Billion US Dollars during this time period.2 Mobile penetration has increased from about 0 in 1989 to around 673 at this moment. Thus it can be safely said that GDP grew by more than 4 times, but how much of this has been contributed directly and indirectly by the Telecommunication Sector?

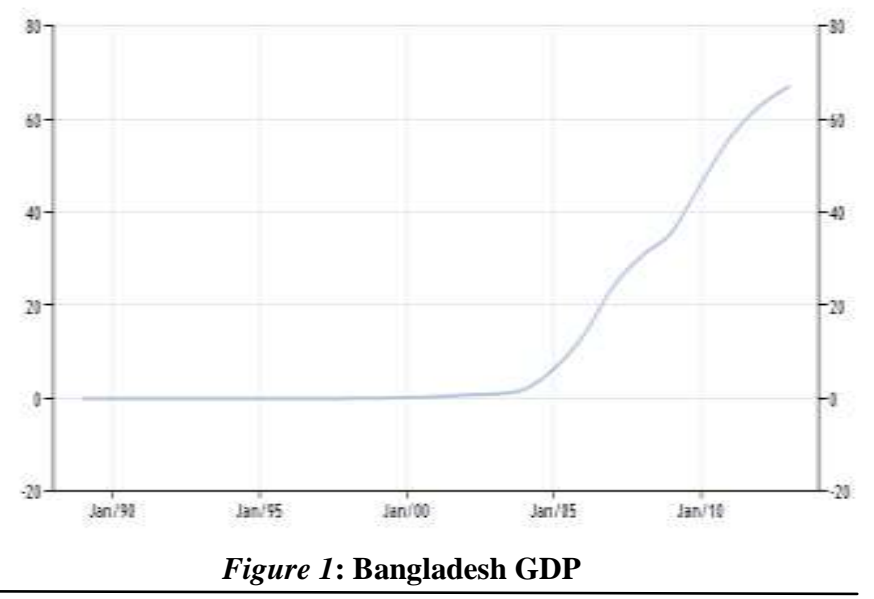

Zaheed Husein Mohammad Al-Din

Senior Lecturer in Human Resource Management,

MBA Program Coordinator,

Green Business School,

Green University of Bangladesh

\section{Overview of the Telecommunication Industry}

When we compare the Mobile Cellular Penetration trend with the GDP Growth Trend of the country we see a similar trend in the two graphs. We can say that the growth of Cellular Industry has contributed to the growth of the country's economy. Bangladesh's Information and Communications Technology (ICT) industry has developed over the past time period of more than a decade, with telecommunications generating total industry investments as of August 2014 of $\$ 4.5$ billion from 2002 and providing about eight percent of the government's total revenue per annum. Ministry of Posts and Telecommunications and the Ministry of Information and Communication has been merged into Ministry of Posts, Telecommunications and Information technology. The rationale behind this merger is to ensure better coordination and reduced bureaucracy. The ministry now has two divisions-Posts and Telecommunication division and Information and Communication Technology division. The Minister of Posts and Telecommunication is in charge of this newly formed ministry.

To mention a few: Start something new, Go beyond, Jole Uthun Apon Soktite, Amader Phone are some of the tag lines of the six cellular operators in Bangladesh. We can see that the operators are promising that they provide convenience and connectivity to the general people. How well have they kept their promises to the people of Bangladesh? Well to tell the truth, before the first mobile operator set foot on Bangladesh, people were heavily dependent on the BTTB Phones which are very popularly known as T\&T Phone Lines. However, at this moment in time BTTB struggles to bring in new customers to their customer base. This is evident from the below graph.

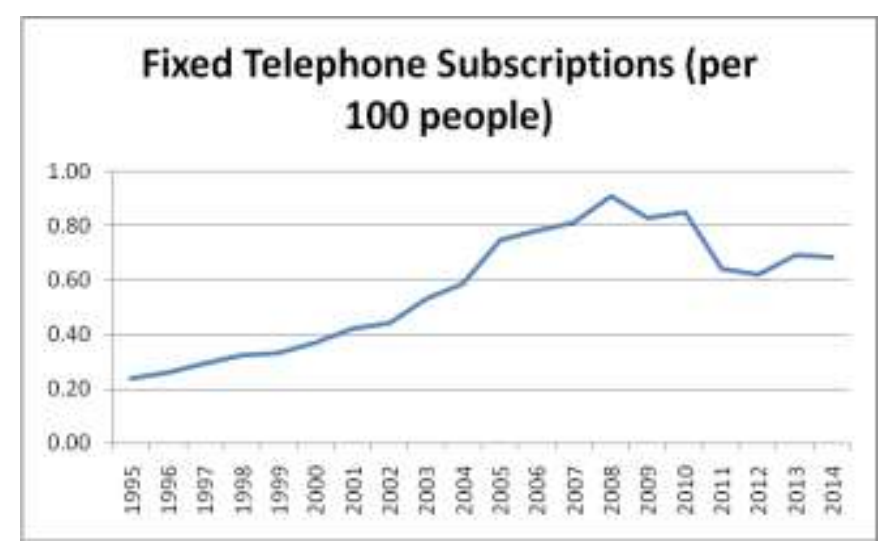

Figure 2: Telephone Subscriptions 
Proc. of The Third Intl. Conf. on Advances in Social Science, Management and Human Behaviour - SMHB 2015

Copyright ( ) Institute of Research Engineers and Doctors, USA .All rights reserved.

ISBN: 978-1-63248-067-5 doi: 10.15224/ 978-1-63248-067-5-71

This has been possible because of the diligent effort by the mobile operators of Bangladesh. Although Bangladesh has one of the highest call rates in the world, the mobile penetration is also at the very high end. This has been possible mainly by catering towards the needs of the people. The six operators together serve a customer base of 120 million as of December 2014.

The operators do not just provide voice services. They have messaging services, Value Added Services, Mobile Financial Solutions and very recently 3G (3rd Generation) mobile services. The graph below demonstrates the explosive growth in internet usage using mobile connection:

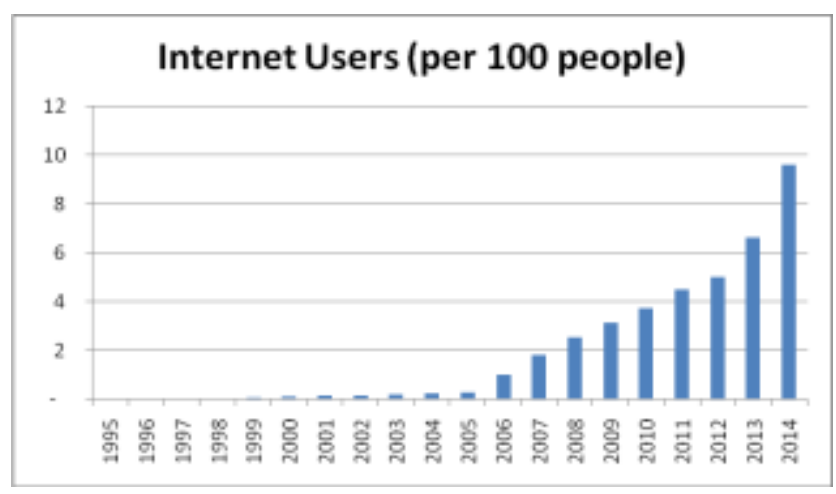

Figure 3: Internet Users

With the 3G Connectivity and with handsets, subscribers can do video chatting besides enjoying high speed data connectivity. Question is how soon we will see in Bangladesh that people are using their cellular device to attend meetings and do video chat online with the newly introduced 3G Connectivity. In the opinion of the writer, the mobile operators need to promote not just their $3 \mathrm{G}$ Connection but also the mobile handsets, which need to accompany the services of the operators.

When one looks at the 6 mobile operators, one would feel that couple of thousands of employees' industry is worth Millions of Dollars. However, everyone would be amazed to know that the Telecommunication Sector employees an additional few thousand employees in the secondary and tertiary levels such as public call offices, recharge booths, distribution, etc. All these together support on average a significant proportion of the people of the country. All the companies together add hundreds of Dollars to the government exchequer in terms of Corporate Tax and a lot more in terms of Value Added Tax and Personal income tax.

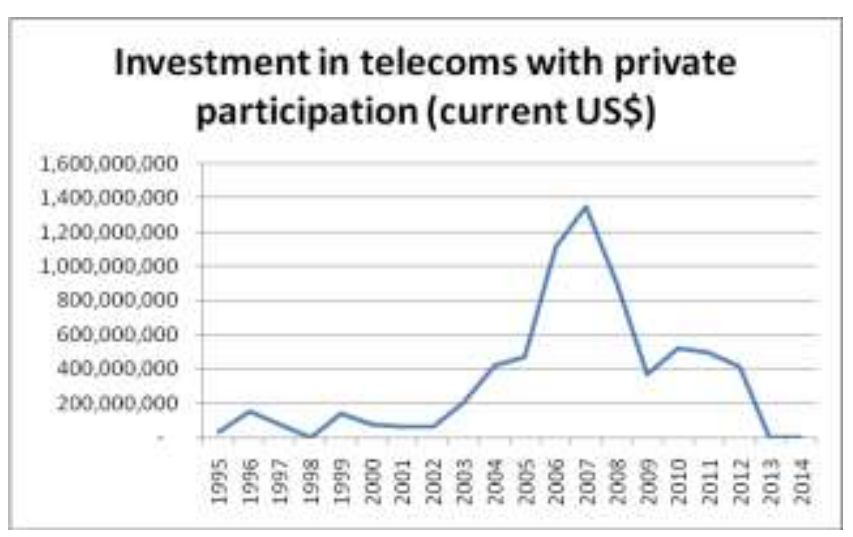

Figure 4: Investment in Telecoms
At present, 6 mobile operators are serving the customers in Bangladesh. These operators, excepting one state owned company, are all in the private sector ownership. These operators do take the profit out of the country to the countries where the parent companies are located. This total

Telecommunication Sector in Bangladesh adds enormously to the GDP and National Exchequer in both direct and indirect ways. It supports many other sectors and plays a pivotal role in the economic growth of the country.

amount came to hundreds of thousands in US Dollars in the last fiscal year. A lot of people, especially many commercially important people have vehemently opposed this flow of money and opposed the establishment of these mobile operators in Bangladesh. However, when one looks at the overall contribution of these operators towards the economy of the country then one would question the challenge that these people do to these companies. This requires more research on the cost-benefit aspects to find out if the establishment of these 5 private operators has been a worthwhile decision or not. The common man's observation would say that it has been a worthwhile decision. Bangladesh has significant competitive advantages in the ICT industry that could be tapped into for economic and social development. The lack of shared IT hosting infrastructure, governance policies, and standards and structures present a major barrier to providing seamless electronic services and improving the public sector's effectiveness and efficiency. The first mobile financial service deployments were launched in Bangladesh in mid2011, and by the end of 2013 they were being used by 22 percent of the population- a fast start for a large country of 160 million inhabitants. In 2013, registered mobile financial services accounts in Bangladesh grew faster than in any other country. Even though Bangladesh's central bank has approved more than 20 licenses to offer mobile financial services, more than 80 percent of transactions are through a single company - bKash Limited. bKash launched in the second half of 2011, grew to 2 million accounts by the end of 2012, and shot up to 11 million registered accounts by the end of 2013. Unlike large mobile money businesses in other countries, bKash is not a mobile network operator (MNO) and did not have an existing customer base to which it added mobile financial services. bKash acquired each client on its own.

\section{E-Commerce: Mobile Banking in Bangladesh}

There are two types of banks, scheduled (licensed to perform all operations of a bank) and non-scheduled (specialized bank with limited functions). Financial Institutions are a third category, limited to specialized financing instruments. Payment system includes Bangladesh Automated Clearing House, Automated Check Processing System, Electronic Funds Transfer, Mobile Financial Services, Online Payment Gateway Service Providers, National Payment Switch, E-Commerce \& M-Commerce, and Legal \& Regulatory Framework.

\section{MFS Overview}

In 2011, Bangladesh Bank regulated that mobile financial service be bank led. Within the Bangladesh Bank 
Proc. of The Third Intl. Conf. on Advances in Social Science, Management and Human Behaviour - SMHB 2015

Copyright (c) Institute of Research Engineers and Doctors, USA .All rights reserved.

ISBN: 978-1-63248-067-5 doi: 10.15224/ 978-1-63248-067-5-71

regulations, banks are allowed using mobile financial services for:

- payments in / out

- transferring inward remittances

- $\quad$ person to person payments

- $\quad$ person to business payments

- business to person payments

- $\quad$ person to government payments

- government to person payments

- other payments (microfinance, insurance premiums)

So far 23 Banks have been granted mobile financial service licenses; 7 have operational services. There are two leaders in the Bangladesh market: BRAC/bKash and DBBL. Banks offer mobile financial services and mobile wallets.

In 2011, the Central Bank issued Mobile Financial Service Guidelines which both clarified mobile banking opportunities for banks, defined clear roles, and signaled support for banking innovation. Through these guidelines, mobile banking had been bank-led. Since 2011, two clear leaders have emerged - BRAC/bKash and Dutch Bangla Bank/ DBBL. Both have extensive partnerships with the MNOs. BRAC/bKash alone has access to $98 \%$ of mobile subscribers, and a vast agent network - an agent in almost every other Bangladesh village. Some more recent estimates note that bKash has over 2 million subscribers, a notable leader in this field. Despite these early advances a number of key issues still remain as it relates to access, usage, and diversification. A number of surveys indicated that awareness of the service is still relatively low, and trust/credibility of the service is preventing adoption. Those who do register for an account are using the service only once, and not deepening their usage or diversification of services. The Banking Sector has responded to the agricultural needs, with increased products (notably cards and green financing) to support development of agriculture (and sustainable agriculture).

The MFI sector continues to grow, but with slower uptake amongst women entrepreneurs and increasing uptake with SMEs - demonstrating market saturation in one area, and market diversification in another. In the last few years the rate of remittance growth has decreased. In the 20112012, however, the rate of growth was higher than in previous years. Mobile Financial Service Guidelines were released in September 2011 (and updated in December 2011). Through these guidelines, mobile financial services are to be bank-led through licensed banks. Banks leverage a network of agents, and are accountable for ensuring that mobile accounts are indeed set up, and compliant with KYC protocol.

\section{Role of Telecommunication Sector}

In Bangladesh the largest structure of privatization become possible due to the investment of different telecommunication companies. The FDI in this sector till September 2008 was Tk. 30 thousand crore. Due to the global recession it slightly decreased in the financial year2009-10. According to a report of world famous Auditing Institution Deloitte, "In developing country, if using of mobile phone increase by $10 \%$, government revenue will increase by $1.2 \%$ in a year." Moreover it plays a significance role to develop the economic condition of Bangladesh.

Job Creation and Reduced Unemployment: To reduce unemployment problem telecom industry plays a vital role by creating employment opportunities in Bangladesh. A study show, till 2008, 675,000 people of the country are directly or indirectly involved in this sector for job and among them $15 \%$ are women. So it also can say this sector also help to empower the women in our country.

Sources of Government Income and Revenue: It is one of the largest sectors for government to get revenue. The contribution of telecom sector in our country's total GDP is around $1.46 \%$ and the major portion of this contribution comes from the mobile phone companies. Till September 2008 , the contribution of this sector to our economy was tk 20 thousands crore which was about $8 \%$ of the total revenues.

Listing in Stock Market: Though telecom started its business in private sector but currently Grameenphone has been listed in stock market and offered shares to the public about tk 486 crore which is a good sign of this sector. This will also help to operate their business and increase public image to the mass people in our country. Shareholders of Grameenphone became profitable which can also help our economy.

Improvements in Communication System: Cellular phone has brought a dramatic change in the communication system in our society. Life has become fast, easy and comfortable in terms of business and society. By using this device we can connect with all over the world within short period of time and also can share information and sophisticated technology.

Inculcating Corporate Culture and Competitiveness: Telecom sector specially phone company is the pioneer to establish the corporate culture in Bangladesh. Now a day, most of the private organization as well as some public organization are practicing this culture which make the market more competitive and the employee, people and government can be benefited from this cultural environment.

Corporate Social Responsibility: The telecommunication section also plays important role by contributing to health, education, environment sports and all other social sector as corporate social responsibility (CSR) it is contributing to cancer hospital, scholarship for the students and arranging different types of training programs for human development. It also contribute to the beautification of our different cities, provide relief in different area, health line and service, make people aware about the environment and doing different types of social works. This sector acts as a member of society. 


\section{Problems Of Telecommunication Sector of Bangladesh}

When we look at the prospects of the telecommunication sector of Bangladesh, certain problems also come to our mind:

High Competition: High competition in mobile or telecommunication sector in the country is one of the main problems. If we have a look at the primary stage of the telecom sector, there was only Citycell and Grameenphone and they were operating their business in their own way. They took the first mover advantages but when Banglalink, Robi, Teletalk, Airtel came to compete in the market then the market became more competitive and still there exist a high competition in this sector. So to face this competition/ challenge some of the operators are thinking to merge their business to survive in the market

Poor Economic Background: Bangladesh has a weak economic background where a significant portion of our people is living under the poverty line. So it is difficult to operate such type of business in Bangladesh while making a remarkable profit. By considering this economic background, the telecom sector may fix the call rate and the government should reduce tax on SIM..

Instable Political Situation: Our previous history tells that Bangladesh is not a politically stable country. Different types of political violence, pressure of army, corruption and many more problems make our country unstable and also has made this sector insecure. If we take a look at last few years our democracy had faced many ups and downs and we don't have any Foreign Direct Investment (FDI) in any of the sector.

High Rate of Corporate Tax: The telecommunication sector is not able to make profit. Moreover they are to pay high corporate tax which is $40 \%-45 \%$. It is another major problem.

SIM Tax: In Bangladesh the mobile operator has to pay high tax for each SIM. Though tax is paid by the subscribers directly but the companies give incentive to continue the sale of the SIM at a lower price in the competitive market to hold their position. But now it has become impossible for all the company to carry on this burden. As the growth rate of the subscriber has declined, the companies are in a challenging position.

Import Tax: In case of technological perspective, Bangladesh is not good enough. So mobile phone operators is to transfer or import technologies, handsets and other equipments related to telecommunication and for this they are to pay $35 \%$ import tax on it. It is also a great problem for this sector to make profit and survive in the market.

\section{Conclusion}

Overall we can say that the telecommunication sector has made significant contribution towards the economy of Bangladesh and its growth. Currently, it is facing few challenges, which need to be addressed. Once these are addressed the industry has the potential to further contribute towards the growth of the economy.

\section{References}

[1] Tenzin Norbhu, Mohan Kharbanda, Siou Chew Kuek, Elli Takagaki, Erika Hoffman-Kiess (2009), Leveraging ICT for Growth and Competitiveness in Bangladesh: IT/ITES Industry Development, The World Bank, June 2009

[2] Lalita Moorty, Zahid Hussain, Md. Abul Basher, Sanjana Zaman, Nadeem Rizwan (2011), Bangladesh Economic Update, The World Bank, June 2011

[3] Graham Friend (2011), Best Practice Spectrum Renewal and Pricing: A review of International best practice and the lessons for the Government of Bangladesh, The World Bank, June 2011

[4] Ms. Farhana Zamil, Md Miraj Hossen (2012), Problems and Prospects of Telecommunication Sector of Bangladesh: A Critical Review, New Media and Mass Communication, Vol 4

[5] IFC, World Bank Group, (2013), IFC Mobile Money Scoping Country Report: Bangladesh, April 2013

[6] The World Bank, Bangladesh Development Update, Poverty Reduction and Economic Management, South Asia Region, April 2014

[7] Gregory Chen, Stephen Rasmussen, (2014), bKash Bangladesh: A Fast Start for Mobile Financial Services, BRIEF CGAP, July 2014

[8] Massimiliano Cali, Thomas Farole, Charles Kunaka, Swarnim Wagle (2014), World Bank Group, Integrating Border Regions: Connectivity and Competitiveness in South Asia, July 2014

[9] World Bank Group (2014): Bangladesh Country Snapshot, October 2014

[10] BTRC Website

[11] CIA World Fact Book

[12] Microfinance Regulatory Authority Bangladesh

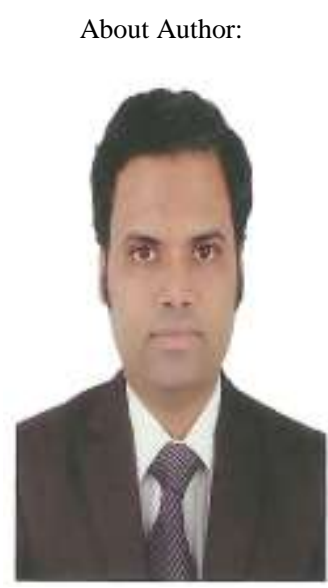

Mr. Zaheed Husein Md Al-Din is currently serving as Senior Lecturer and MBA Program Coordinator in Green Business School, Green University of Bangladesh. He did his Bachelor of Business Administration and Master of Business Administration from Institute of Business Administration, University of Dhaka, Bangladesh. Prior to that he completed his A'Level with 3 A Grades where he achieved highest mark in Physics, O'Level with 10 A Grades both under Edexcel International, London Board of Examination, from Dhaka. He has experience of working in a leading Multinational Telecommunication Company in Bangladesh for more than six and half years. 